\title{
Pinwheel Flap as an Option to Reconstruct a Nasal Defect: A Series of Two Cases
}

\author{
Rogério Nabor Kondo ${ }^{1^{*}}$ (D), Ariane Itimura Cestari² (D), Bruno Mendes Soares² (iD, Fabiana \\ De Mari Scalone 2 (iD and Silvia Irla Alfaro Yabar ${ }^{2}$ iD
}

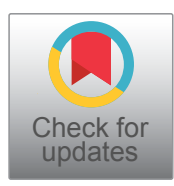

${ }^{1}$ Department of Dermatology, Northern Paraná Regional University Hospital, State University of Londrina, Brazil

${ }^{2}$ Department of Dermatology, Regional University Hospital of Northern Paraná, State University of Londrina, Brazil

\begin{abstract}
Introduction: Basal cell carcinoma (BCC) is the most common skin cancer. When located in the nasal region and the resulting defect is greater than 3 centimeters becomes challenging for the dermatological surgeon. The pinwheel technique (PWT) is a rotating flap to correct defects, mainly on the scalp, but we use it to close two nasal defects after $\mathrm{CBC}$ excision.
\end{abstract}

Objectives and methods: We report two cases of BCCs located in the nasal region and reconstructed with a pinwheel flap.

Results and conclusions: In both cases, the results were satisfactory, both for cosmetics and functionality.

Keywords

Basal cell carcinoma, Flap Pinwheel technique

\section{Introduction}

Basal cell carcinoma (BCC) is the most common type of skin câncer [1]. Sometimes, the complete excision of this type of tumor requires a flap to close the resulting defect $[1,2]$. As for the reconstruction of larger defects, greater than 30 millimeters $(\mathrm{mm})$, in the nasal region, still become more challenging for the dermatological surgeon, due to local characteristics such as rigid structure and little mobility [3].

Pinwheel technique (PWT) is a flap with rotation flaps created to correct circular defects in the scalp, a place that has limited skin mobility $[4,5]$. Some surgeons have also used PWT for the temporal region without pilification [4].

We report two cases of patients with nasal BCC, in which we chose the PWT for reconstruction, with satisfactory aesthetic results. The purpose of the case report is to demonstrate an option of the technique to correct wide defects in the nasal region (not yet described for the region), with easy execution and a good level of patient satisfaction.

\section{Methods}

Two patients with BCC in the nasal region were treated:

Patient 1: Female patient, 81-years-old, phototype III, from Londrina (PR), with erythematous plaque, $24 \mathrm{~mm} \times 21 \mathrm{~mm}$, on the lateral dorsum to the right of the nasal region, compatible with $\mathrm{BCC}$ by biopsy. The lesion was excised with safety margins of $5 \mathrm{~mm}$. The resulting defect was $34 \mathrm{~mm}$ in the longest axis and PWT was chosen (Figure 1, Figure 2 and Figure 3).

Patient 2: Female patient, 68-years-old, phototype II, from Londrina (PR), with erythematous plaque, $35 \mathrm{~mm} \times 20 \mathrm{~mm}$, on the right side of the nasal region, compatible with BCC by biopsy. The lesion was excised with safety margins of $5 \mathrm{~mm}$. The resulting defect was $45 \mathrm{~mm}$ in the longest axis and PWT was chosen (Figure 4, Figure 5, Figure 6, Figure 7 and Figure 8).

Technique description (Figure 2, Figure 4, Figure 5 and Figure 6):
a) Patient in a horizontal supine position;
b) Marking with methylene blue or surgical pen of the

\begin{abstract}
*Corresponding author: Rogério Nabor Kondo, Dermatologist and Assistant Professor, Department of Dermatology, Northern Paraná Regional University Hospital, State University of Londrina, Ayrton Senna da Silva Avenue, 1055, room 1205 - Gleba Fazenda Palhano, Londrina - PR, 86050-460, Brazil, Tel: 33360144; 3336-0104

Accepted: May June 01, 2021

Published online: June 03, 2021

Citation: Kondo RN, Cestari Al, Soares BM, et al. (2021) Pinwheel Flap as an Option to Reconstruct a Nasal Defect: A Series of Two Cases. Dermatol Arch 5(1):122-126
\end{abstract}


Citation: Kondo RN, Cestari Al, Soares BM, et al. (2021) Pinwheel Flap as an Option to Reconstruct a Nasal Defect: A Series of Two Cases. Dermatol Arch 5(1):122-126

lesion and flap incision sites: glabellar area, left alar nasal, right alar nasal and right nasofacial sulcus (Figure 1);

c) Antisepsis with $10 \%$ topical polyvinyl iodine from the nasal and glabellar regions;

d) Placing surgical drapes;

e) Infiltrative anesthesia of the nasal and glabellat sites with $2 \%$ lidocaine with vasoconstrictor;

f) Circular incision of the lesion with blade size 15 and block excision of the piece;

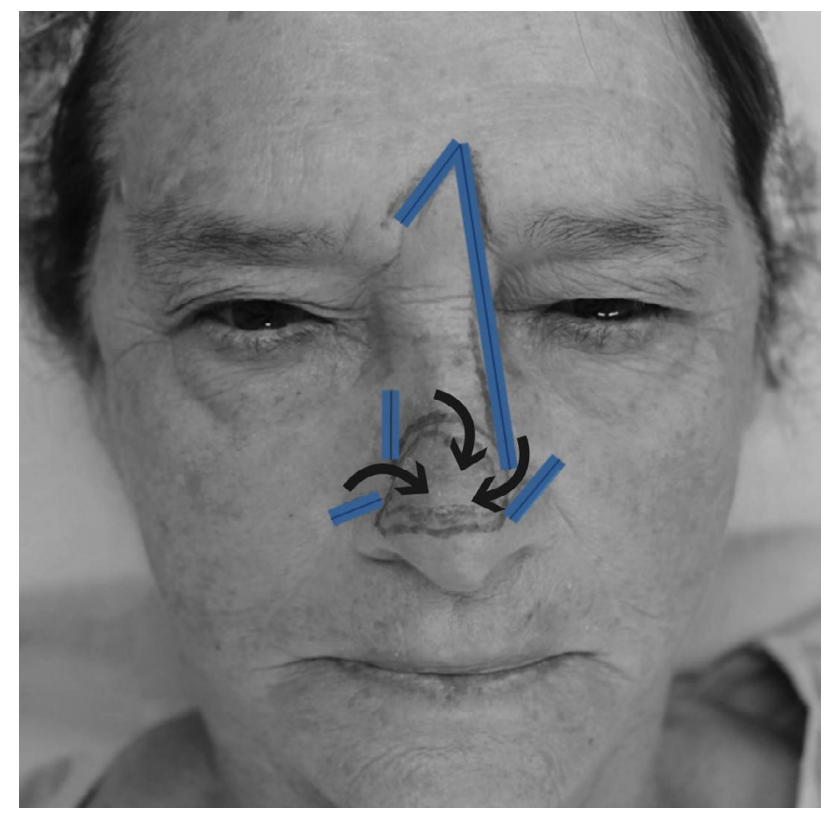

Figure 1: Patient 1- Delimitation of the lesion and the pre-established margins. Marking of "flap" incisions (glabellar, nasal alar sulcus on the left, nasal alar sulcus on the right and nasofacial sulcus on the right).

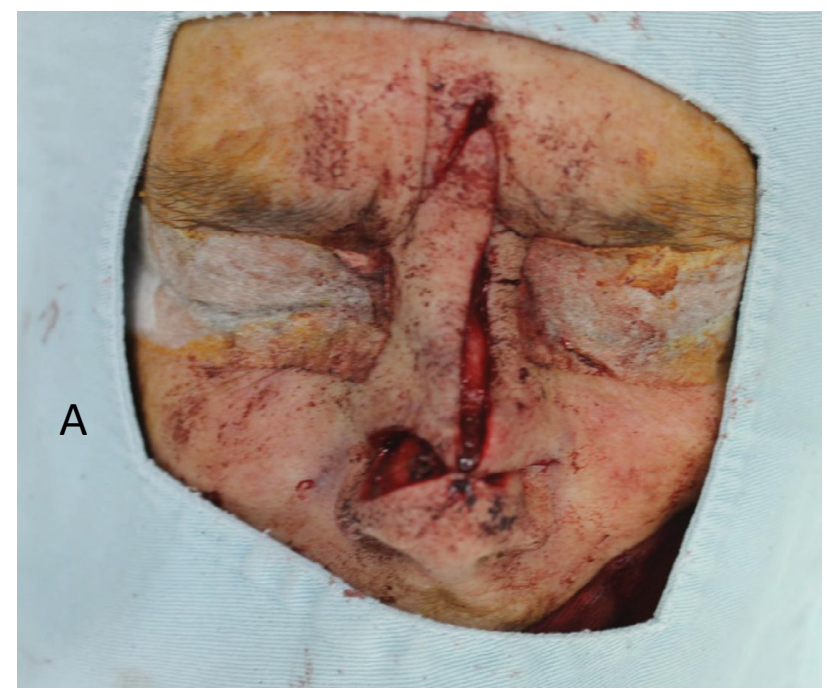

g) Hemostasis;

h) Incision and cutaneous divulsion of the glabellar flap;

i) Positioning the glabellar flap with 5.0 mononylon, single stitches;

j) Incision and detachment of the flap in the alar sulcus on the left;

k) Positioning the alar sulcus flap on the left with 5.0 mononylon, single stitches;

I) Incision and detachment of the flap in the right alar sulcus;

m) Positioning the alar sulcus flap on the right with 5.0 mononylon, single stitches;

n) Incision and detachment of the flap in the right nasofacial sulcus;

o) Positioning of the right nasofacial groove flap with 5.0 mononylon, simple stitches;

p) Local cleaning with saline;

q) Occlusive dressing.

\section{Results}

Patient 1: Patient was fine in the immediate postoperative period, without infection or hemorrhages. She did not present recurrences of the lesion after 4 months with satisfactory aesthetic and functional results (Figure 3 ).

Patient 2: Patient responded well in the immediate postoperative period, without infection or hemorrhages. She did not present recurrences of the lesion after 3 months with satisfactory aesthetic and functional results (Figure 8).

\section{Discussion}

Several techniques are used for reconstruction of defects in the nasal region, such as primary closure, AT flaps, glabel-

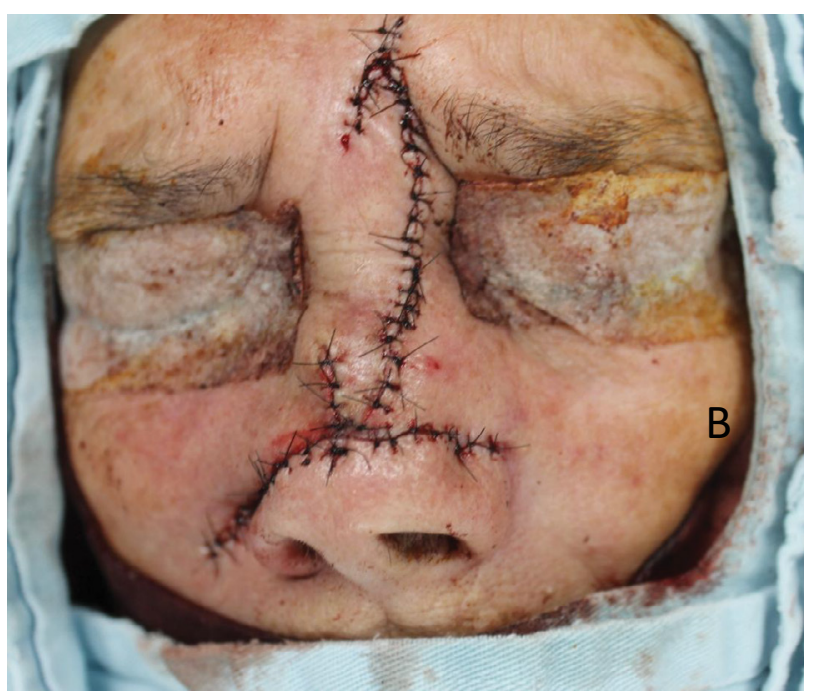

Figure 2: (A) Flap with the glabellar flaps, the nasal alar groove on the left, the nasal alar groove on the right and the nasofacial groove on the right positioned; (B) Flaps sutured. 
Citation: Kondo RN, Cestari Al, Soares BM, et al. (2021) Pinwheel Flap as an Option to Reconstruct a Nasal Defect: A Series of Two Cases. Dermatol Arch 5(1):122-126
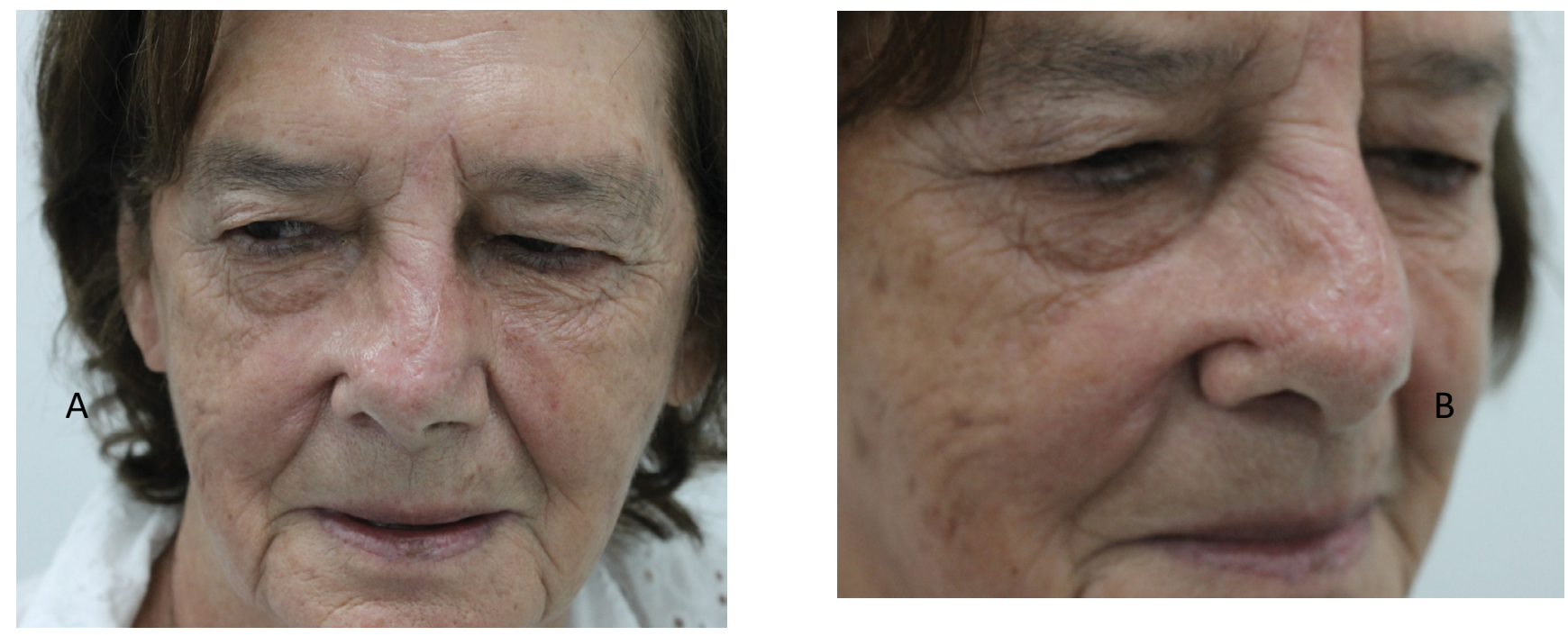

Figure 3: (A and B) Patient 1 after 4 months of post-surgey.
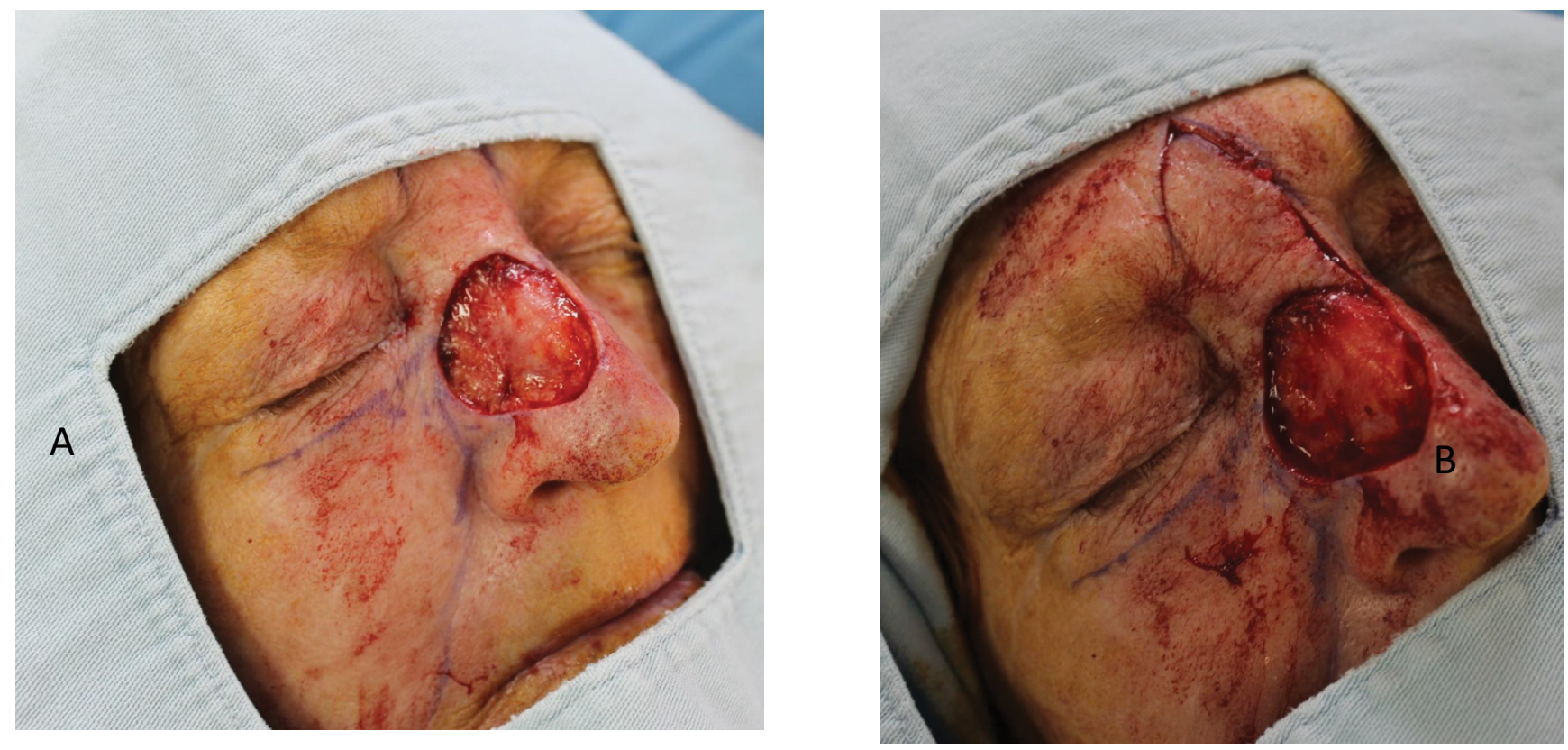

Figure 4: (A) Patient 2- Nasal defect; (B) Patient 2- Incision of the glabellar flap.
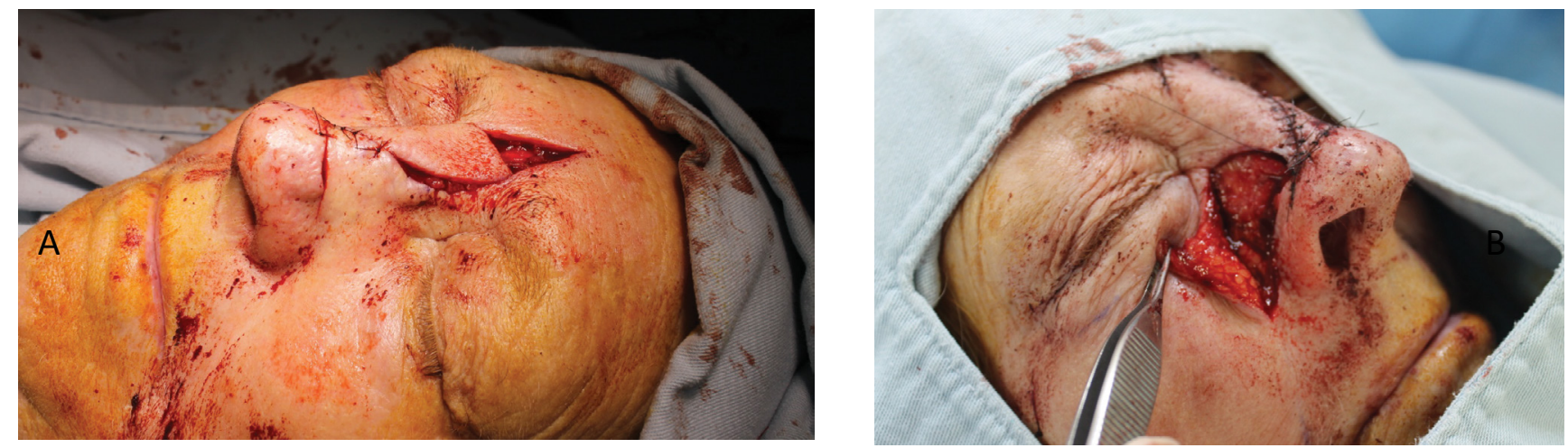

Figure 5: (A) Glabellar flap and left nasal sulcus groove positioned; (B) Flap of the right nasal alar groove and right naso facial groove detached to be positioned. 
Citation: Kondo RN, Cestari Al, Soares BM, et al. (2021) Pinwheel Flap as an Option to Reconstruct a Nasal Defect: A Series of Two Cases. Dermatol Arch 5(1):122-126
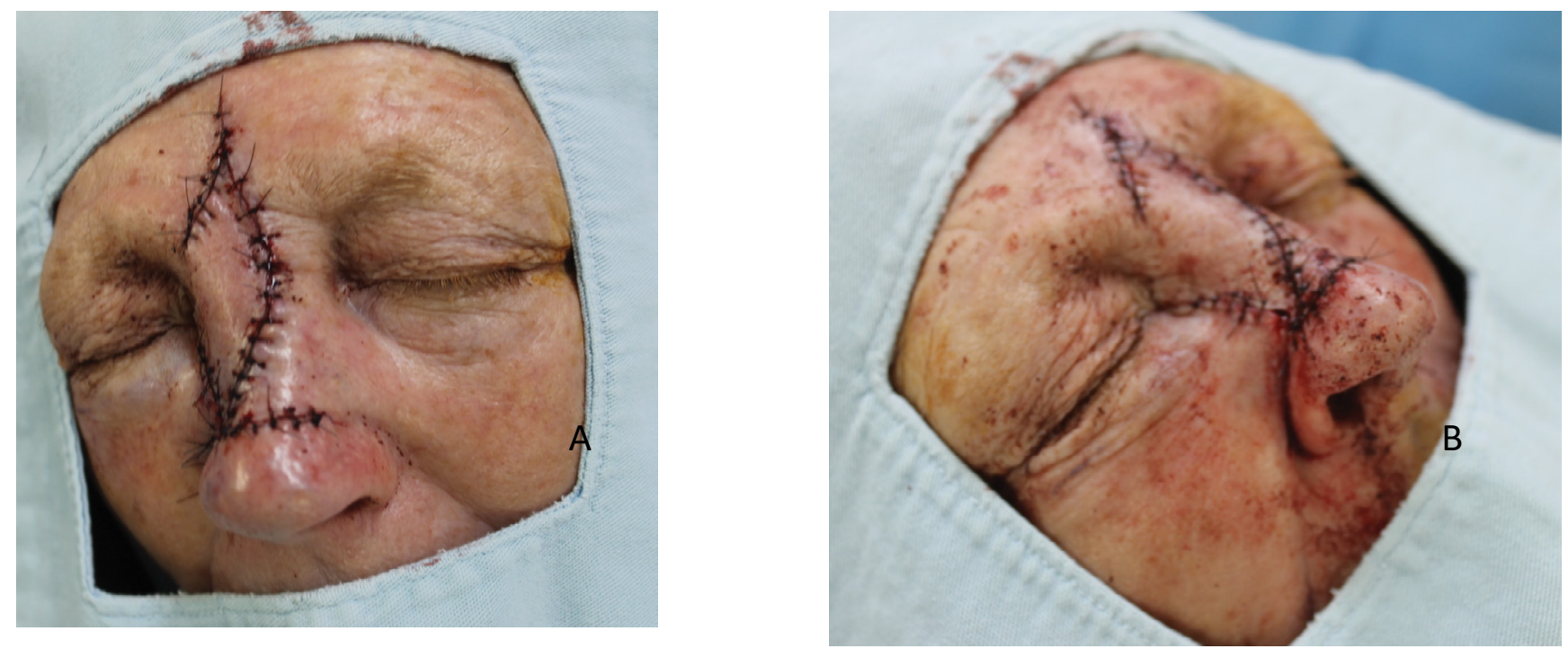

Figure 6: (A) Flap with flaps of glabellar rotation and sutured left nasal sulcus; (B) Flap with flaps of the nasal alar sulcus on the left and of the right nasofacial sulcus sutured.
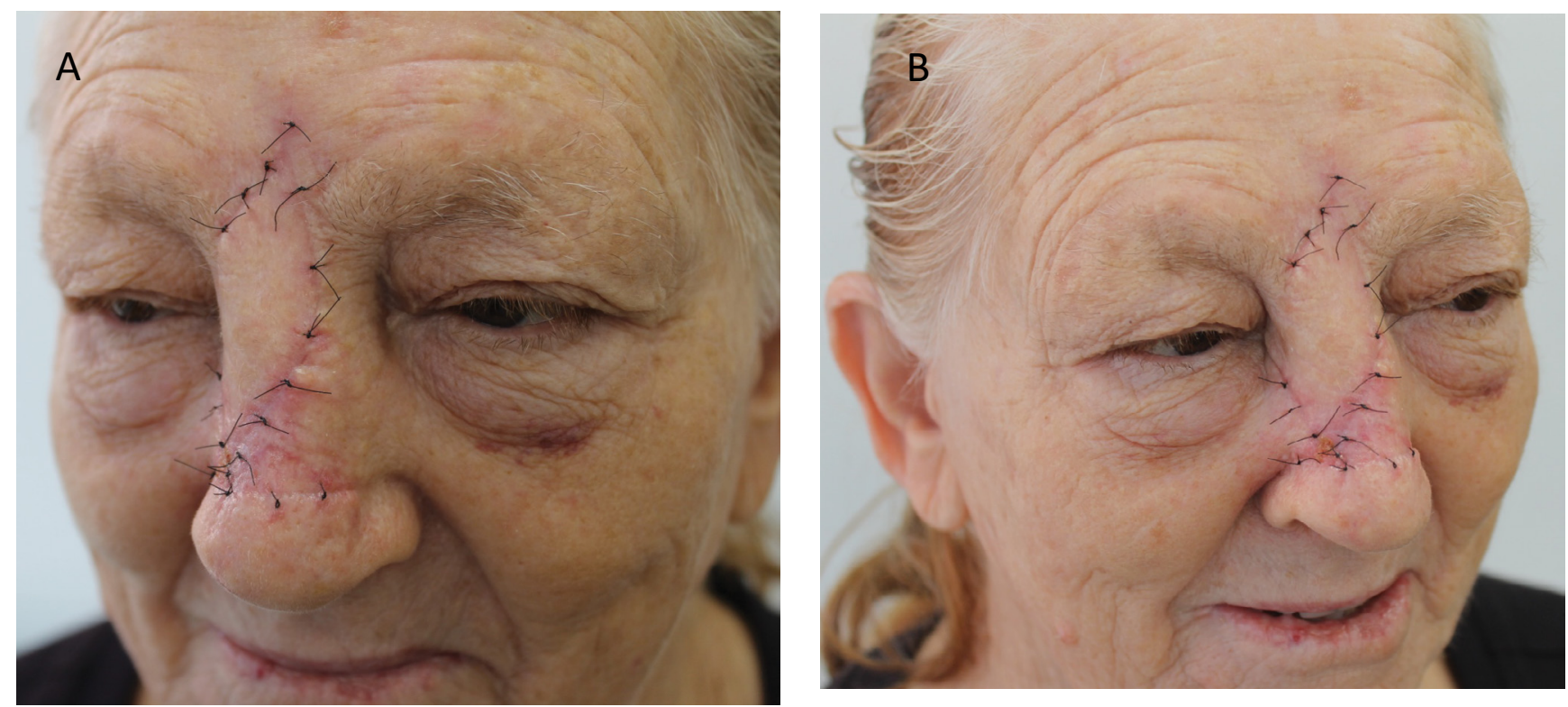

Figure 7: (A and B) Patient 2 at one week post-surgery.
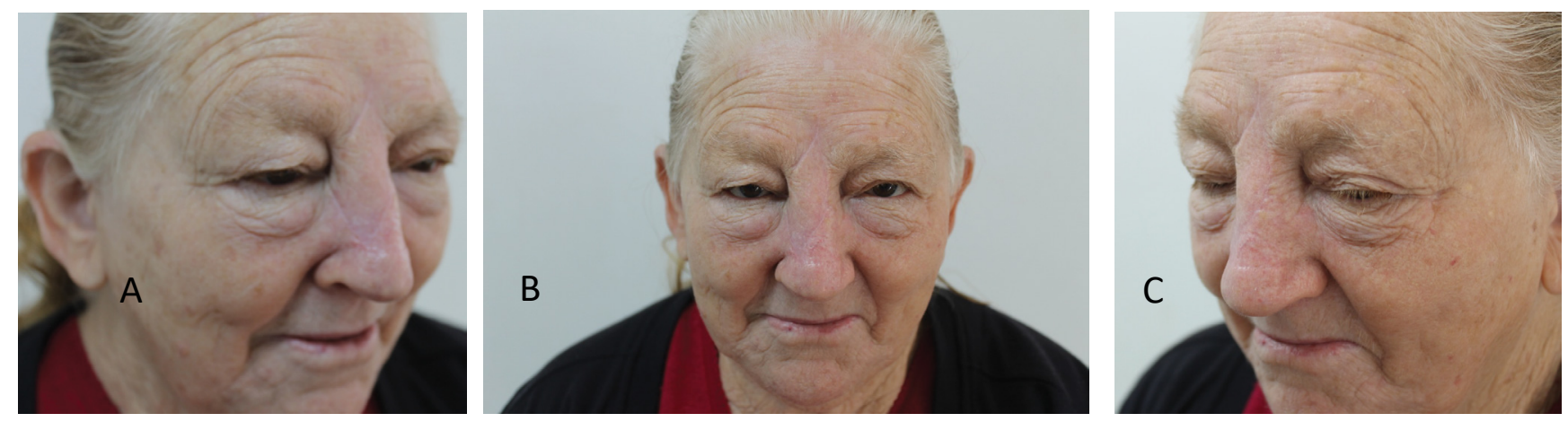

Figure 8: (A, B and C) Patient 2 at 3 months post-surgery. 
lar advancement, island advancement, glabellar rotation, bilobed, rhomboid and grafting $[1,3,6]$. All proposals aim to produce good functionality and a great cosmetic result, in addition to tumor resolution.

In the present cases, primary closings were not possible. We chose flaps instead of grafts, aiming at better aesthetic results. But due to the size of the defects, the cases have become even more challenging.

Micrographic surgery (Mohs) is widely recommended to avoid major removal of healthy skin and to avoid large defects. But surgery with safety margins is still well accepted [7]. Our service does not have a surgeon specialized in Mohs and, therefore, it was chosen for excesses with predetermined margins.

The reason for not having a description, so far, of PWT in the nasal region, perhaps is due to the cosmetic subunits of the region, which is why the multiple rotation flaps could, supposedly, mix these subunits resulting in an inadequate cosmetic.

The first flap of the flap was not a simple rotation, but a glabellar rotation. This execution allows greater coverage of the defect. The second flap, respecting the clockwise direction, uses a rotation of the left alar nasal sulcus. The third flap, a rotation of the right nasal sulcus. The fourth flap, a rotation of the right nasofacial sulcus. Most scars were hidden in the natural sulcus.

Pinwheel technique (PWT), proposed by the present authors to solve wide defects in the nasal region, is valid. The site has limited mobility of the adjacent skin and the creation of several tabs with their corresponding cosmetic units leaves the final result acceptable and functional.

\section{Conclusion}

The use of PWT can be a good option for the resolution of large defects secondary to the excision of cutaneous tumors in the nasal region.

\section{Authors Declaration}

Work carried out by the dermatology service of the University Hospital of Northern Paraná - State University of Londrina, Brazil.

\section{Interest Conflict}

None.

\section{Financial Support}

None.

\section{References}

1. Kondo RN, Gon AS, Pontello R Jr (2019) Recurrence rate of basal cell carcinoma in patients submitted to skin flaps or grafts. An Bras Dermatol 94: 442-445.

2. Kondo RN, Pontello R Jr (2015) A-T flap for the reconstruction of an operative wound in the malar region. Surg Cosmetic Dermatol 7: 272-274.

3. Nicolacópulos T, Kondo RN (2018) Retalho A-T para reconstrução de ferida operatória na ponta nasal. Surg Cosmetic Dermatol 10: 165-167.

4. Simsek T, Eroglu L (2013) Versatility of the pinwheel flap to reconstruct circular defects in the temporal and scalp region J Plast Surg Hand Surg 47: 97-101.

5. Varnalidis I, Mantelakis A, Spiers HVM, et al. (2019) Application of the pinwheel flap for closure of a large defect of the scalp. BMJ Case Rep 12: e229420.

6. Cerci FB (2018) Versatility of advancement flaps for nasal reconstruction following Mohs micrographic surgery. An Bras Dermatol 93: 719-722.

7. Matsushita S, Nakamura Y, Tanaka R, et al. (2020) Prediction of the invasive level of basal cell carcinomas in the facial area: Analysis of 718 Japanese cases. J Dermatol Sci 99: 152-157.

DOI: $10.36959 / 661 / 317$

Copyright: (C) 2021 Kondo RN, et al. This is an open-access article distributed under the terms of the Creative Commons Attribution License, which permits unrestricted use, distribution, and reproduction in any medium, provided the original author and source are credited. 